\title{
Reduction in sperm aneuploidy levels in severe oligoasthenoteratospermic patients after medical therapy: a preliminary report
}

\author{
Giorgio Cavallini ${ }^{1}$, Maria Cristina Magli ${ }^{2}$, Andor Crippa ${ }^{2}$, Anna Pia Ferraretti $^{3}$ and Luca Gianaroli ${ }^{3}$
}

The objective of this study was to investigate whether medical therapy can reduce sperm aneuploidy levels and improve the results of intracytoplasmic sperm injection (ICSI) in patients with severe idiopathic oligoasthenoteratospermia (OAT). Thirty-three infertile couples requiring ICSI because of severe idiopathic OAT after at least one unsuccessful ICSI cycle were considered. Semen parameters (concentration, motility and morphology), the percentage of aneuploid sperm and the results of ICSI (the number of oocytes fertilized, embryos transferred, biochemical pregnancies, clinical pregnancies and live births) were compared before and after a 3-month course of treatment with $L$-carnitine $1 \mathrm{~g}$ given twice per day+acetyl- $L$-carnitine $500 \mathrm{mg}$ given twice per day+one 30-mg cinnoxicam tablet every 4 days. Aneuploidy was assessed using fluorescent in situ hybridisation (FISH) performed on chromosomes X, Y, 13, 15, 16, 17, 18,21 and 22. The results showed that 22 of the 33 patients had a reduced frequency of aneuploid sperm and improved sperm morphology after treatment (group 1), and 11 showed no change (group 2). The numbers of biochemical pregnancies, clinical pregnancies and live births were significantly higher in group 1 than in group 2 . No significant difference was found between the groups regarding the numbers of oocytes fertilized and embryos transferred. The side effects were negligible. The numbers of ICSI pregnancies and live births in severe idiopathic OAT patients improved with a course of $L$-carnitine, acetyl- $L$-carnitine and cinnoxicam. Asian Journal of Andrology (2012) 14, 591-598; doi:10.1038/aja.2012.23; published online 30 April 2012

Keywords: acetyl-L-carnitine; cinnoxicam; ICSI; L-carnitine; male infertility; oligoasthenoteratospermia; sperm aneuploidy

\section{INTRODUCTION}

Men with non-obstructive azoospermia or severe oligoasthenoteratospermia (OAT) have been shown to have significantly higher frequencies of sperm aneuploidy. ${ }^{1}$ Aneuploid sperm may retain the ability to fertilize an oocyte through intracytoplasmic sperm injection (ICSI), but there is a possibility that the resultant embryo will be negatively affected, resulting in impaired rates of successful embryo transfer, implantation, pregnancy and live birth. ${ }^{2-4}$ Furthermore, approximately 5\% of children born through ICSI are at an increased risk of chromosomal anomalies because of the de novo aberrations that arise during gametogenesis of their parents. This percentage is much higher than the expected value of $0.5 \%$ in the general population. ${ }^{5,6}$

There have been few previous reports describing reductions in sperm aneuploidy levels, the relationship between sperm aneuploidy and natural or assisted reproduction, and the associated changes in sperm concentration, motility and morphology. A significant reduction in sperm aneuploidy levels has been detected after varicocele repair $^{7}$ and in men with idiopathic OAT who were treated with traditional Chinese medicine ${ }^{8}$ or with recombinant follicle-stimulating hormone (FSH). ${ }^{9}$ Improvements in sperm concentration, motility and morphology occurred in the study involving varicocele repair, ${ }^{7}$ but not in the studies involving treatment with traditional Chinese medicine or FSH. ${ }^{8,9}$ No study has evaluated whether a reduction in sperm aneuploidy is associated with an improvement in natural and/ or assisted reproductive fathering.

We have demonstrated that $L$-carnitine, acetyl- $L$-carnitine and cinnoxicam treatment improved sperm concentration, motility and morphology and increased the number of naturally occurring pregnancies among the partners of men with idiopathic OAT. ${ }^{10} L$-carnitine transports energy substrates into the mitochondria and improves energy production, thus increasing energy availability and decreasing the generation of reactive oxygen species. It also improves the action of metabolic enzymes by buffering the acyl-Coenzime A (CoA): CoA ratio and shuttles dangerous Acyl groups out of the mitochondria and cells, thus protecting cell membranes from damage. Acetyl- $L$-carnitine is a source of readily available energy (the so-called 'activated acetyl groups') for utilisation in the Krebs cycle, and it supports the incorporation of phospholipids into cellular membranes, leading to higher membrane stability. Cinnoxicam may enhance these activities. ${ }^{10}$ The aim of this study was to determine whether carnitine + cinnoxicam administration can improve sperm motility, concentration and morphology, reduce sperm aneuploidy frequencies and improve ICSI success rates in severe OAT patients.

${ }^{1}$ Medicitalia, Andrological Section Outpatient Clinic of Ferrara, Ferrara 44100, Italy; ${ }^{2}$ Laboratory of Assisted Reproduction, Società Italiana di Medicina della Riproduzione (SISMER), Bologna 40138, Italy and ${ }^{3}$ Operative Unit of Assisted Reproduction, Società Italiana di Medicina della Riproduzione (SISMER), Bologna 40138, Italy Correspondence: Dr G Cavallini (giorgiocavallini@libero.it)

Received: 31 August 2011; Revised: 14 November 2011; Accepted: 10 February 2012; Published online: 30 April 2012 


\section{MATERIALS AND METHODS}

The study was authorized by the Società Italiana di Studi di Medicina della Riproduzione (SISMER) Institutional Review Board. We compared ICSI outcomes before and after medical treatment for severe idiopathic OAT.

\section{Study participants}

All primary infertile couples requiring ICSI at SISMER as a result of male severe idiopathic OAT were candidates for the study. Severe OAT was defined as a sperm concentration $<2 \times 10^{6} \mathrm{ml}^{-1}$ in each of two semen sample analyses. ${ }^{11}$ The inclusion criterion was men with severe OAT whose partners had undergone at least one ICSI cycle performed with freshly ejaculated spermatozoa and fresh oocytes resulting in no pregnancy. The study period extended from 1 April 2003 to 12 June 2010. One hundred and twenty-eight couples were considered, and 53 were studied (the mean age of the male partner was $37.2 \pm 4.6$ years). The exclusion criteria have previously been presented, ${ }^{10}$ and 29 couples were excluded. Additional exclusion criteria were smoking (10 cases), alcohol consumption ( 2 cases), female factors for infertility (20 cases), ${ }^{12}$ a poor response to controlled ovarian stimulation $(2 \text { cases })^{12}$ and males who did not yield a sufficient number of spermatozoa with ejaculation $(<5000 \text { spermatozoa per ejaculation })^{1}$ to perform a fluorescent in situ hybridisation (FISH) test (12 cases). The participants in the study were asked not to change their diet, and there was $100 \%$ compliance. Patients affected by severe idiopathic OAT were assessed as previously indicated. ${ }^{13}$

\section{Variables assessed}

The male partner variables assessed and compared before and after a 3month intervention were as follows: sperm concentration, motility and morphology and the percentage of aneuploid sperm detected with FISH. The evaluation of the incidence of aneuploidy followed a conservative approach by doubling the incidence of disomy. ${ }^{13}$ The lack of a hybridisation signal for each of the chromosomes studied was not taken into account because, although these sperm may be theoretically nullisomic for one of these chromosomes, it is impossible to distinguish between nullisomies and hybridisation failures. ${ }^{13}$

The following female partner variables were compared between the ICSI cycles carried out before and after male therapy: the numbers of oocytes collected, injected and fertilized (defined as the presence of two distinct pronuclei $16-18 \mathrm{~h}$ after sperm injection), the number of embryos transferred (embryos were transferred 4 days after injection, i.e., at the eight-cell stage), the number of biochemical pregnancies (detected by measuring serum $\beta$-hCG on at least two occasions 14 days after embryo transfer), and the numbers of clinical pregnancies (defined as detectable heart activity), miscarriages and live births (defined as any birth event in which at least one baby was born alive and survived for $>1$ month).

\section{Male partner variables}

Semen analysis. Two semen samples were collected before drug administration and at 90-100 days after drug administration. Each patient delivered two semen samples by masturbation after $72 \mathrm{~h}$ of abstinence; the samples were collected within 7-10 days of each other. Each sample was assessed according to the WHO guidelines. ${ }^{11}$ The morphological assessments were conducted using strict criteria. ${ }^{14}$

FISH procedure. FISH analysis was carried out on one of the two semen samples collected from each patient. A single technician (AC) who is experienced with FISH analysis performed all the analyses to avoid interoperator variability. The first or second semen sample was used according to the availability of the technician AC in the laboratory. Multicolour FISH was used in a twostep protocol to detect chromosomes X, Y, 13, 15, 16, 17, 18, 21 and 22 in each sperm cell as previously indicated. ${ }^{15}$ The probe mixture used in the first round contained the probes specific for chromosomes 13, 16, 18, 21 and 22. A second round followed, with probes specific for chromosomes X, Y, 15 and 17 (Multivysion PB panel from Vysis; Vysis Inc., Downers Grove, IL, USA). The sperm were scored according to the three criteria previously described: (i) the sperm were diagnosed as abnormal if they presented two or more fluorescent signals with a size and intensity similar to the size and intensity of the same chromosome detected in normal nuclei; diploidy was defined by the presence of two signals for each of the chromosomes studied in the presence of the sperm tail and an oval head shape; the sperm were defined as nullisomic when no fluorescent signals appeared; (ii) all signals were separated from each other by at least a single domain; and (iii) overlapping spermatozoa or sperm heads without a well-defined boundary were not evaluated. $^{15}$

At present, the identification of a normal threshold or normal range of variation for the percentage of aneuploid sperm is regarded as impossible, because notable differences exist among laboratories. ${ }^{13}$ Thus, data related to aneuploidy in all severe OAT patients included in the study were considered.

FISH analysis of one semen sample was regarded as sufficient, because the intra-individual variability was assessed for two semen samples obtained from the same individual at different time points, i.e., 1-4 months apart. Fifteen patients underwent analysis of the intraindividual variability in the course of preparatory FISH tests. The variability was not statistically significant $(0.90<$ Pearson coefficients<0.93). ${ }^{16}$

\section{The study intervention}

The male patients used oral $L$-carnitine $2 \times 1 \mathrm{~g}$ day $^{-1}$ (Carnitene; Sigma-Tau, Rome, Italy) + oral acetyl- $L$-carnitine $2 \times 500 \mathrm{mg}$ day $^{-1}$ (Nicetile; Sigma-Tau) + one $30 \mathrm{mg}$ Cinnoxicam tablet (Sinartrol; SPA, Milan, Italy) every 4 days. ${ }^{10}$ Only fresh ejaculated spermatozoa were used for the ICSI cycles after therapy. Cinnoxicam suppositories were used in a previous study, ${ }^{10}$ but this drug is no longer marketed; we therefore used Cinnoxicam tablets.

Controlled ovarian stimulation, induction of multiple follicular growth, oocyte collection and luteal support were performed as previously described. ${ }^{17}$ All metaphase II oocytes were injected, and a maximum of two embryos were transferred until March 2004; a maximum of three metaphase II oocytes were injected per patient, and a maximum of three embryos were transferred after 1 April 2004 according to Italian legislation on assisted reproduction (Parliament of the Italian Republic 2004 (http://www.camera.it/parlam/leggi/ 04040l.htm)). Only fresh oocytes were used.

\section{Data management and statistical analysis}

The preliminary nature of the study supported the application of early stopping rules because of the benefit of using the O'Brien-Fleming stopping boundaries. ${ }^{18}$ The Kruskal-Wallis test was used to compare medians. The Fisher $\chi^{2}$ exact test was used to analyse the differences in proportional data. ${ }^{16}$

We planned 'a priori' to compare the ICSI outcomes between the patients who had reduced frequencies of aneuploid sperm (group 1) and the patients in whom there was no reduction (group 2) (see 
the 'Discussion' section). The grouping was completed 'a posteriori' therefore, the data were analysed with a 'post hoc test', the $G$ test (utmost plausibility test). ${ }^{16}$

We planned in advance to evaluate the relationship between the hormonal data and changes in the percentage of the aneuploid spermatozoa after therapy using multivariate regression analysis. No significant correlation was found, and these data have not been presented in the interest of brevity.

The side effects were recorded. Congenital malformations of the newborns were investigated using the clinical files of the departments where the deliveries occurred.

\section{RESULTS}

Fifty-three couples were admitted to the study. Five couples had their ICSI cycles suspended (five cases with risk of ovarian hyperstimulation syndrome), six patients violated the protocol, and nine were lost to follow up (sperm aneuploidy levels were reduced in three of these patients; the levels increased in two of them and the frequency of aneuploid sperm did not change after therapy in four patients). Thus, 33 couples completed the study, and their demographic data are presented in Table 1 .

The data for each patient regarding the percentage of nullisomic and disomic spermatozoa for each chromosome studied and the total percentage of disomic, nullisomic and aneuploid sperm before and after therapy are presented in Table 2 . This table also indicates the number of spermatozoa examined per subject before and after treatment. A total of 194652 spermatozoa were evaluated for aneuploidies before the intervention (i.e., a mean of $5901 \pm 305$ (s.d.) spermatozoa per patient), and 193397 spermatozoa were evaluated after the intervention (i.e., a mean of $5878 \pm 234$ (s.d.) spermatozoa per patient). As expected (see the 'Materials and methods' section), some patients (22) exhibited a significant reduction in sperm aneuploidy levels coincident with drug administration, and some patients (11) exhibited levels of sperm aneuploidy that did not change during the drug course.

According to our research plan, group 1 comprised 22 patients with significantly reduced sperm aneuploidy levels (responders), whereas group 2 comprised 11 patients with no reduction (non-responders). Tables 3 and 4 present the changes of the variables assessed in the patients of groups 1 and 2 . The sperm variables are presented in Table 3, and the ICSI variables are presented in Table 4. In group 1, 19 out of 22 patients underwent one ICSI cycle each, whereas the other three patients underwent two ICSI cycles each. In group 2, all 11 patients underwent one ICSI cycle each. Sperm concentration and motility, as well as the numbers of oocytes collected, injected and fertilized, the number of embryos transferred and the number of miscarriages did not significantly differ between the groups. The reduction in sperm aneuploidy levels and changes in sperm morphology, as well as the numbers of biochemical pregnancies, clinical pregnancie and live births, were significantly better in group 1 than in group 2. No malformations were observed in the newborns. The side effects of the therapy were mild euphoria (two cases $(6 \%)$ ) and epigastric pain (one case (3\%)), and they did not require drug suspension.

\section{DISCUSSION}

Based on the comparison between group 1 (responders) and group 2 (non-responders), we found that lower levels of sperm aneuploidy and more normal sperm morphology are associated with more favourable ICSI outcomes, including the number of biochemical pregnancies, clinical pregnancies and live births. By contrast, sperm concentration and motility, as well as the numbers of oocytes fertilized, embryos transferred and miscarriages, did not differ significantly between the two groups. Our data confirm the link between sperm morphology and aneuploidy and indicate that morphology is a semen parameter that seems to be independent of sperm concentration and motility. ${ }^{13}$ Our results support the view that sperm morphology is the most informative semen measurement for discriminating fertile men from infertile men. ${ }^{14}$ The outcome of ICSI is also believed to be linked to sperm concentration ${ }^{19,20}$ and/or to sperm motility. ${ }^{20,21}$ However, these data cannot be compared to the data presented here, because our patients were treated with carnitines + oxicam, but no treatment was administered to the patients in the former studies. Other authors maintain that sperm aneuploidy levels are likely to be inversely related to sperm morphology, sperm motility or sperm concentration. ${ }^{12,22}$ However, the computerized cell scanning system has demonstrated the relationship between chromosomal aberrations and sperm morphology in the same spermatozoon. ${ }^{23}$ Furthermore, the studies supporting a relationship between sperm aneuploidy levels and sperm motility or sperm concentration contain methodological biases; namely, only a small number of patients were tested and/or few (one to three) autosomes + XY chromosomes were assessed and/or the statistical analyses used were based on thresholds, whereas sperm concentration, motility and morphology, and the percentage of aneuploid spermatozoa are continuous variables. ${ }^{12,22}$

The absence of a placebo-treated group may be a potential source of bias in this study; therefore, we should consider that the treatment results attained may also be due to the vehicles used in the drug production.

The restrictions of Italian law regarding assisted reproduction (2004, http://www.camera.it/parlam/leggi/04040l.htm) and the private nature

\section{Table 1 Demographic data of the population studied (33 couples)}

\begin{tabular}{|c|c|c|}
\hline & Male partners (mean \pm s.d.) & Female partner (mean \pm s.d.) \\
\hline Age (year) & $36.9 \pm 5.0$ & - \\
\hline FSH $\left(I U I^{-1}\right)$ & $11.8 \pm 5.0$ & - \\
\hline $\mathrm{LH}\left(\mathrm{IU} \mathrm{I}^{-1}\right)$ & $4.7 \pm 1.5$ & - \\
\hline $\mathrm{T}\left(\mathrm{nmol} \mathrm{I}^{-1}\right)$ & $17.0 \pm 3.9$ & - \\
\hline $\mathrm{fT}\left(\mathrm{pg} \mathrm{ml^{-1 }}\right)$ & $12.0 \pm 2.4$ & - \\
\hline $\operatorname{PRL}\left(\mu \mathrm{g} \mathrm{ml}^{-1}\right)$ & $7.8 \pm 2.0$ & - \\
\hline tPSA (ng ml $\left.{ }^{-1}\right)$ & $1.2 \pm 0.3$ & - \\
\hline Number of patients with chromosomal aberrations & 0 & - \\
\hline Number of ICSI cycles carried out before enrolment in this study & - & $1.9 \pm 1.5$ (range $1-6)$ \\
\hline $\begin{array}{l}\text { Time elapsed (months) between the ICSI cycles performed before } \\
\text { and after drug administration }\end{array}$ & - & $7.4 \pm 3.5$ \\
\hline
\end{tabular}


Table 2 Sperm aneuploidy frequencies detected using the FISH test in 33 severe idiopathic OAT patients BT and AT

\begin{tabular}{|c|c|c|c|c|c|c|c|c|c|c|c|c|c|c|}
\hline \multirow[t]{2}{*}{ Patient no. } & \multirow{2}{*}{$\begin{array}{c}\text { Number of sperm } \\
\text { examined }\end{array}$} & \multicolumn{11}{|c|}{ Frequency (\%) of disomic and nullisomic spermatozoa for the following chromosomes } & \multirow{2}{*}{$\begin{array}{l}\text { Aneuploidy } \\
\text { level (\%) }\end{array}$} & \multirow[t]{2}{*}{$\chi^{2}$} \\
\hline & & & & $X, Y$ & 13 & 15 & 16 & 17 & 18 & 21 & 22 & Total & & \\
\hline \multicolumn{15}{|c|}{22 patients significantly reduced their sperm aneuploidy levels AT } \\
\hline & & & Nul.\% & 10.5 & 7.6 & 3.0 & 2.7 & 2.1 & 3.0 & 7.5 & 7.7 & 10.9 & & \\
\hline & 5847 & AT & Dis. $\%$ & 2.0 & 1.1 & 0.5 & 0.2 & 0.1 & 0.1 & 2.0 & 1.7 & 2.5 & 5 & \\
\hline & & & Nul.\% & 2.0 & 1.0 & 0.4 & 0.3 & 0.1 & 0.1 & 2.1 & 1.6 & 2.6 & & \\
\hline \multirow{2}{*}{2} & 5467 & AT & Dis. \% & 2.1 & 1.8 & 0.9 & 0.8 & 0.5 & 0.4 & 2.0 & 2.1 & 2.5 & 5 & \\
\hline & & & Nul.\% & 2.0 & 1.8 & 0.9 & 0.7 & 0.5 & 0.3 & 2.0 & 2.1 & 2.5 & & \\
\hline \multirow[t]{4}{*}{5} & 5607 & BT & Dis. \% & 6.7 & 5.9 & 3.3 & 3.9 & 3.1 & 2.5 & 6.2 & 6.1 & 7.4 & 14.8 & $14.987 * *$ \\
\hline & & & Nul.\% & 6.6 & 5.9 & 3.2 & 4.0 & 3.0 & 2.4 & 6.0 & 6.0 & 7.3 & & \\
\hline & 5502 & AT & Dis. \% & 1.4 & 1.0 & 0.2 & 0.2 & 0.1 & 0.1 & 1.3 & 1.3 & 1.6 & 3.2 & \\
\hline & & & Nul.\% & 1.4 & 1.0 & 0.1 & 0.2 & 0.1 & 0.1 & 1.2 & 1.2 & 1.6 & & \\
\hline & & & Nul.\% & 9.6 & 8.6 & 4.3 & 5.1 & 4.0 & 3.5 & 7.8 & 7.4 & 10.1 & & \\
\hline & 5890 & AT & Dis. \% & 0.9 & 0.8 & 0.4 & 0.6 & 0.4 & 0.4 & 0.8 & 0.7 & 1.0 & 2.0 & \\
\hline & & & Nul.\% & 0.9 & 0.8 & 0.4 & 0.5 & 0.3 & 0.3 & 0.8 & 0.7 & 1.0 & & \\
\hline 10 & 5889 & BT & Dis. \% & 6.8 & 6.0 & 3.1 & 3.2 & 2.9 & 2.5 & 6.1 & 6.2 & 7.5 & 15.0 & $7.112 * *$ \\
\hline & & & Nul.\% & 6.9 & 6.0 & 3.0 & 3.2 & 2.8 & 2.4 & 6.0 & 6.3 & 7.4 & & \\
\hline & 5600 & AT & Dis.\% & 1.0 & 0.9 & 1.0 & 1.1 & 0.6 & 0.5 & 0.9 & 0.9 & 1.6 & 3.2 & \\
\hline & & & Nul.\% & 1.1 & 1.0 & 1.0 & 1.0 & 0.5 & 0.5 & 0.9 & 0.8 & 1.6 & & \\
\hline 12 & 6005 & BT & Dis.\% & 8.0 & 8.2 & 4.8 & 5.3 & 4.0 & 4.5 & 7.4 & 6.0 & 8.6 & 17.2 & $19.117 * *$ \\
\hline & & & Nul.\% & 8.2 & 8.5 & 4.5 & 5.1 & 4.2 & 4.6 & 7.6 & 6.0 & 8.7 & & \\
\hline & 6211 & AT & Dis. $\%$ & 0.5 & 0.7 & 0.2 & 0.2 & 0.1 & 0.1 & 0.5 & 0.5 & 1.0 & 2.0 & \\
\hline & & & Nul.\% & 0.5 & 0.8 & 0.2 & 0.2 & 0.1 & 0.2 & 0.5 & 0.6 & 1.2 & & \\
\hline 13 & 5902 & BT & Dis. $\%$ & 7.4 & 8.4 & 4.6 & 3.0 & 4.3 & 4.2 & 7.1 & 6.2 & 8.5 & 17.0 & $18.778 * *$ \\
\hline & & & Nul.\% & 3.9 & 3.7 & 2.0 & 2.1 & 2.1 & 1.8 & 3.8 & 3.0 & 4.7 & & \\
\hline & 6432 & AT & Dis. \% & 0.4 & 0.4 & 0.1 & 0.2 & 0.1 & 0.1 & 0.4 & 0.3 & 0.5 & 1.0 & \\
\hline & & & Nul.\% & 0.4 & 0.4 & 0.2 & 0.1 & 0.1 & 0.1 & 0.5 & 0.3 & 0.5 & & \\
\hline 18 & 5803 & BT & Dis. $\%$ & 9.4 & 8.8 & 4.6 & 4.4 & 4.0 & 3.7 & 9.0 & 8.4 & 10.2 & 20.4 & $10.100 * *$ \\
\hline & & & Nul.\% & 9.2 & 8.3 & 4.2 & 4.3 & 3.8 & 3.5 & 9.0 & 8.0 & 9.9 & & \\
\hline & 5891 & AT & Dis.\% & 0.7 & 0.6 & 0.4 & 0.3 & 0.3 & 0.3 & 0.6 & 0.5 & 1.0 & 2.0 & \\
\hline & & & Nul.\% & 0.6 & 0.5 & 0.3 & 0.3 & 0.2 & 0.2 & 0.6 & 0.4 & 0.9 & & \\
\hline 19 & 5932 & BT & Dis. $\%$ & 2.0 & 1.9 & 1.0 & 0.9 & 0.8 & 0.6 & 2.0 & 1.6 & 4.4 & 8.8 & $5.413^{*}$ \\
\hline & & & Nul.\% & 2.2 & 1.8 & 1.0 & 0.8 & 0.7 & 0.7 & 2.0 & 1.7 & 4.6 & & \\
\hline & 5800 & AT & Dis. \% & 0.6 & 0.5 & 0.3 & 0.2 & 0.1 & 0.1 & 0.6 & 0.5 & 1.0 & 2.0 & \\
\hline & & & Nul.\% & 0.7 & 0.4 & 0.1 & 0.2 & 0.2 & 0.1 & 0.6 & 0.5 & 1.0 & & \\
\hline 24 & 6301 & BT & Dis. \% & 4.0 & 3.7 & 2.5 & 2.3 & 1.7 & 1.8 & 3.7 & 3.2 & 4.8 & 9.6 & $5.614 *$ \\
\hline & & & Nul.\% & 4.0 & 3.6 & 2.5 & 2.2 & 1.6 & 1.6 & 3.6 & 3.5 & 4.8 & & \\
\hline & 5897 & AT & Dis. $\%$ & 1.0 & 0.9 & 0.3 & 0.3 & 0.2 & 0.1 & 0.9 & 0.9 & 1.6 & 3.2 & \\
\hline & & & Nul.\% & 1.1 & 1.0 & 0.4 & 0.2 & 0.3 & 0.1 & 1.0 & 1.1 & 1.8 & & \\
\hline 25 & 5851 & BT & Dis. \% & 6.8 & 6.6 & 5.4 & 4.8 & 3.6 & 3.2 & 6.5 & 6.5 & 7.7 & 15.4 & $7.434 * *$ \\
\hline & & & Nul.\% & 7.0 & 6.3 & 5.4 & 4.9 & 3.5 & 3.4 & 6.4 & 6.4 & 8.0 & & \\
\hline & 5914 & AT & Dis. \% & 0.7 & 0.6 & 0.3 & 0.2 & 0.2 & 0.1 & 0.6 & 0.5 & 1.0 & 2.0 & \\
\hline & & & Nul.\% & 0.6 & 0.6 & 0.3 & 0.2 & 0.2 & 0.1 & 0.5 & 0.5 & 0.9 & & \\
\hline 26 & 5609 & BT & Dis. \% & 6.9 & 6.2 & 5.1 & 4.6 & 4.0 & 3.6 & 6.4 & 6.2 & 7.9 & 15.8 & $8.112^{* *}$ \\
\hline & & & Nul.\% & 6.5 & 5.9 & 4.9 & 4.4 & 4.1 & 4.4 & 6.0 & 6.0 & 7.5 & & \\
\hline & 5760 & AT & Dis. \% & 0.7 & 0.5 & 0.3 & 0.2 & 0.2 & 0.1 & 0.6 & 0.5 & 1.0 & 2.0 & \\
\hline & & & Nul.\% & 0.8 & 0.5 & 0.2 & 0.2 & 0.1 & 0.2 & 0.6 & 0.4 & 1.2 & & \\
\hline
\end{tabular}


Table 2 (Continued) Sperm aneuploidy frequencies detected using the FISH test in 33 severe idiopathic OAT patients BT and AT ${ }^{\mathrm{a}}$

\begin{tabular}{|c|c|c|c|c|c|c|c|c|c|c|c|c|c|c|}
\hline \multirow[t]{2}{*}{ Patient no. } & \multirow{2}{*}{$\begin{array}{c}\text { Number of sperm } \\
\text { examined }\end{array}$} & \multicolumn{11}{|c|}{ Frequency (\%) of disomic and nullisomic spermatozoa for the following chromosomes } & \multirow{2}{*}{$\begin{array}{l}\text { Aneuploidy } \\
\text { level (\%) }\end{array}$} & \multirow[t]{2}{*}{$\chi^{2}$} \\
\hline & & & & $X, Y$ & 13 & 15 & 16 & 17 & 18 & 21 & 22 & Total & & \\
\hline \multirow[t]{4}{*}{27} & 6201 & BT & Dis. $\%$ & 6.6 & 6.4 & 5.0 & 5.0 & 4.5 & 4.0 & 6.4 & 6.0 & 7.4 & 14.8 & $9.110 * *$ \\
\hline & & & Nul.\% & 6.5 & 6.0 & 4.7 & 4.9 & 4.3 & 3.9 & 6.2 & 6.0 & 7.3 & & \\
\hline & 5902 & AT & Dis. $\%$ & 0.3 & 0.3 & 0.2 & 0.2 & 0.1 & 0.2 & 0.3 & 0.2 & 0.5 & 1.0 & \\
\hline & & & Nul.\% & 0.3 & 0.3 & 0.3 & 0.1 & 0.2 & 0.1 & 0.3 & 0.3 & 0.6 & & \\
\hline \multirow[t]{4}{*}{28} & 6123 & BT & Dis. $\%$ & 6.8 & 6.2 & 5.5 & 5.0 & 4.4 & 4.0 & 6.5 & 5.8 & 8.0 & 16.0 & $13.119 * *$ \\
\hline & & & Nul.\% & 7.1 & 6.2 & 5.6 & 5.0 & 4.3 & 4.0 & 6.6 & 6.0 & 8.2 & & \\
\hline & 5987 & AT & Dis.\% & 0.4 & 0.3 & 0.2 & 0.2 & 0.2 & 0.1 & 0.3 & 0.3 & 0.6 & 1.2 & \\
\hline & & & Nul.\% & 0.3 & 0.3 & 0.2 & 0.2 & 0.2 & 0.1 & 0.3 & 0.3 & 0.6 & & \\
\hline \multirow[t]{4}{*}{29} & 5250 & BT & Dis. \% & 9.0 & 8.3 & 6.5 & 7.0 & 5.0 & 5.3 & 8.5 & 8.0 & 10.5 & 20.1 & $13.009 * *$ \\
\hline & & & Nul.\% & 9.0 & 7.8 & 6.6 & 7.2 & 5.3 & 4.9 & 8.6 & 7.9 & 11.0 & & \\
\hline & 5988 & AT & Dis. \% & 0.3 & 0.2 & 0.1 & 0.1 & 0.1 & 0.1 & 0.3 & 0.2 & 0.4 & 0.8 & \\
\hline & & & Nul.\% & 0.3 & 0.2 & 0.1 & 0.1 & 0.1 & 0.1 & 0.3 & 0.2 & 0.4 & & \\
\hline \multirow[t]{4}{*}{30} & 5201 & BT & Dis. \% & 4.9 & 4.5 & 3.1 & 3.8 & 3.2 & 3.2 & 4.6 & 4.2 & 5.5 & 11.0 & $5.786 *$ \\
\hline & & & Nul.\% & 5.0 & 4.4 & 3.0 & 3.2 & 3.0 & 3.4 & 4.8 & 4.0 & 6.0 & & \\
\hline & 5902 & AT & Dis. \% & 0.3 & 0.2 & 0.1 & 0.1 & 0.1 & 0.1 & 0.3 & 0.2 & 0.5 & 1.0 & \\
\hline & & & Nul.\% & 0.3 & 0.2 & 0.1 & 0.1 & 0.1 & 0.1 & 0.3 & 0.2 & 0.6 & & \\
\hline \multirow[t]{4}{*}{31} & 6212 & BT & Dis. \% & 3.9 & 3.5 & 2.0 & 2.8 & 2.3 & 2.0 & 3.5 & 3.2 & 4.5 & 9.0 & $5.545 *$ \\
\hline & & & Nul.\% & 4.0 & 3.5 & 2.1 & 2.5 & 2.3 & 2.0 & 3.6 & 3.3 & 4.7 & & \\
\hline & 5903 & AT & Dis. \% & 0.3 & 0.3 & 0.2 & 0.3 & 0.2 & 0.1 & 0.3 & 0.2 & 0.5 & 1.0 & \\
\hline & & & Nul.\% & 0.3 & 0.3 & 0.2 & 0.1 & 0.2 & 0.1 & 0.3 & 0.3 & 0.6 & & \\
\hline 32 & 5907 & BT & Dis.\% & 8.7 & 8.0 & 4.0 & 5.0 & 4.6 & 4.2 & 8.4 & 7.6 & 10.0 & 20.0 & $16.118 * *$ \\
\hline & & & Nul.\% & 8.1 & 8.2 & 4.2 & 4.8 & 4.3 & 4.0 & 8.2 & 7.4 & 9.5 & & \\
\hline & 6011 & AT & Dis. \% & 0.3 & 0.3 & 0.1 & 0.1 & 0.1 & 0.1 & 0.3 & 0.2 & 0.5 & 1.0 & \\
\hline & & & Nul.\% & 0.3 & 0.2 & 0.1 & 0.1 & 0.1 & 0.1 & 0.3 & 0.2 & 0.5 & & \\
\hline 33 & 5950 & BT & Dis.\% & 7.6 & 7.0 & 4.8 & 5.2 & 4.6 & 4.0 & 7.4 & 7.0 & 8.5 & 17.0 & $14.122 * *$ \\
\hline & & & Nul.\% & 7.9 & 6.8 & 4.6 & 5.4 & 4.4 & 4.1 & 7.4 & 6.0 & 8.7 & & \\
\hline & 6047 & AT & Dis. \% & 0.4 & 0.3 & 0.1 & 0.1 & 0.1 & 0.1 & 0.3 & 0.2 & 0.6 & 1.2 & \\
\hline & & & Nul.\% & 0.3 & 0.3 & 0.1 & 0.1 & 0.1 & 0.1 & 0.3 & 0.1 & 0.5 & & \\
\hline 11 patients $\mathrm{d}$ & d not exhibit signifi & sant $r e$ & ons in th & sperm & uploidy & rels $A T$ & & & & & & & & \\
\hline 3 & 5700 & BT & Dis. \% & 3.0 & 2.9 & 1.6 & 1.7 & 1.6 & 1.5 & 3.0 & 3.2 & 3.4 & 6.8 & $2.114^{\S}$ \\
\hline & & & Nul.\% & 3.1 & 2.9 & 1.4 & 1.7 & 1.5 & 1.5 & 1.9 & 2.9 & 3.3 & & \\
\hline & 5850 & AT & Dis. \% & 2.1 & 1.9 & 0.7 & 0.8 & 0.6 & 0.9 & 2.0 & 2.0 & 2.5 & 5 & \\
\hline & & & Nul.\% & 2.1 & 1.8 & 0.6 & 0.8 & 0.6 & 0.9 & 2.0 & 2.0 & 2.4 & & \\
\hline 4 & 5600 & BT & Dis. \% & 6.9 & 6.0 & 3.0 & 3.1 & 2.8 & 2.4 & 7.0 & 5.9 & 7.6 & 15.2 & $1.918^{\S}$ \\
\hline & & & Nul.\% & 6.8 & 6.1 & 3.1 & 3.2 & 2.7 & 2.3 & 6.9 & 5.9 & 7.7 & & \\
\hline & 5551 & AT & Dis. $\%$ & 5.0 & 5.0 & 2.5 & 3.6 & 2.0 & 1.9 & 5.5 & 5.0 & 6.0 & 12.0 & \\
\hline & & & Nul.\% & 5.0 & 5.0 & 2.5 & 3.6 & 2.0 & 1.8 & 5.4 & 5.0 & 6.0 & & \\
\hline 8 & 5950 & BT & Dis. \% & 5.8 & 5.9 & 3.4 & 4.0 & 3.0 & 2.5 & 6.0 & 5.8 & 7.3 & 14.6 & $2.098^{\S}$ \\
\hline & & & Nul.\% & 5.7 & 6.7 & 3.6 & 4.3 & 3.2 & 4.2 & 6.2 & 6.1 & 7.4 & & \\
\hline & 5999 & AT & Dis. \% & 5.8 & 5.9 & 2.4 & 3.0 & 2.1 & 4.1 & 5.0 & 5.1 & 6.0 & 12.0 & \\
\hline & & & Nul.\% & 5.6 & 5.1 & 2.7 & 3.0 & 2.4 & 4.3 & 5.2 & 5.2 & 6.0 & & \\
\hline 9 & 6331 & BT & Dis. $\%$ & 3.0 & 2.7 & 1.3 & 1.5 & 1.8 & 1.2 & 2.6 & 2.4 & 3.3 & 6.6 & $2.112^{\S}$ \\
\hline & & & Nul.\% & 3.1 & 2.8 & 1.4 & 1.5 & 1.9 & 1.3 & 2.7 & 2.5 & 3.5 & & \\
\hline & 5874 & AT & Dis. \% & 3.4 & 3.2 & 1.5 & 2.0 & 2.1 & 1.2 & 2.9 & 2.7 & 4.0 & 8 & \\
\hline & & & Nul.\% & 3.6 & 3.2 & 1.6 & 2.0 & 2.1 & 1.2 & 3.0 & 2.7 & 4.1 & & \\
\hline 11 & 6114 & BT & Dis. \% & 7.6 & 8.4 & 4.0 & 4.2 & 3.8 & 3.4 & 9.1 & 9.1 & 10.1 & 20.2 & $1.116^{\S}$ \\
\hline & & & Nul.\% & 7.7 & 8.6 & 4.0 & 4.3 & 3.6 & 3.5 & 9.0 & 9.0 & 10.5 & & \\
\hline & 5879 & AT & Dis. \% & 8.0 & 7.6 & 3.0 & 3.3 & 3.8 & 2.4 & 8.4 & 8.0 & 9.1 & 18.2 & \\
\hline & & & Nul.\% & 8.0 & 7.7 & 3.0 & 3.4 & 3.7 & 2.6 & 8.0 & 8.1 & 9.3 & & \\
\hline 14 & 6015 & BT & Dis. \% & 7.9 & 6.0 & 4.0 & 4.2 & 3.8 & 3.5 & 7.0 & 5.8 & 8.9 & 17.8 & $2.115^{\S}$ \\
\hline & & & Nul.\% & 8.0 & 6.2 & 4.1 & 4.4 & 3.9 & 3.6 & 7.0 & 5.3 & 9.2 & & \\
\hline & 5552 & AT & Dis. \% & 7.0 & 5.4 & 3.6 & 3.8 & 3.4 & 3.0 & 6.2 & 5.0 & 8.0 & 16.0 & \\
\hline & & & Nul.\% & 7.4 & 5.0 & 3.7 & 3.9 & 3.5 & 3.0 & 6.2 & 5.0 & 8.2 & & \\
\hline 17 & 6133 & BT & Dis. \% & 10.0 & 9.0 & 4.2 & 4.1 & 3.6 & 3.2 & 9.5 & 8.4 & 11 & 22.0 & $2.345^{\S}$ \\
\hline & & & Nul.\% & 9.7 & 8.9 & 4.0 & 3.9 & 3.4 & 3.0 & 9.2 & 8.3 & 10.5 & & \\
\hline & 6245 & AT & Dis.\% & 8.6 & 7.7 & 3.8 & 3.6 & 3.0 & 2.8 & 8.1 & 7.3 & 9.1 & 18.2 & \\
\hline & & & Nul.\% & 8.4 & 8.1 & 4.1 & 3.8 & 3.2 & 3.0 & 8.0 & 7.6 & 9.9 & & \\
\hline 20 & 6110 & $\mathrm{BT}$ & Dis. \% & 4.6 & 4.0 & 2.5 & 2.0 & 1.8 & 1.6 & 4.2 & 3.5 & 10.1 & 20.2 & $2.443^{\S}$ \\
\hline & & & Nul.\% & 4.6 & 3.9 & 2.2 & 1.8 & 2.2 & 1.6 & 4.4 & 3.2 & 10.4 & & \\
\hline & 5902 & AT & Dis.\% & 4.2 & 3.7 & 2.6 & 2.0 & 2.2 & 1.7 & 3.8 & 3.6 & 8.7 & 17.4 & \\
\hline & & & Nul.\% & 4.3 & 3.6 & 2.3 & 1.9 & 2.0 & 1.8 & 3.6 & 3.4 & 8.5 & & \\
\hline
\end{tabular}


Table 2 (Continued) Sperm aneuploidy frequencies detected using the FISH test in 33 severe idiopathic OAT patients BT and AT ${ }^{\mathrm{a}}$

\begin{tabular}{|c|c|c|c|c|c|c|c|c|c|c|c|c|c|c|}
\hline \multirow[t]{2}{*}{ Patient no. } & \multirow{2}{*}{$\begin{array}{c}\text { Number of sperm } \\
\text { examined }\end{array}$} & \multicolumn{11}{|c|}{ Frequency (\%) of disomic and nullisomic spermatozoa for the following chromosomes } & \multirow{2}{*}{$\begin{array}{c}\text { Aneuploidy } \\
\text { level (\%) }\end{array}$} & \multirow[t]{2}{*}{$\chi^{2}$} \\
\hline & & & & $X, Y$ & 13 & 15 & 16 & 17 & 18 & 21 & 22 & Total & & \\
\hline \multirow[t]{3}{*}{21} & 5700 & BT & Dis. \% & 6.8 & 6.4 & 4.6 & 4.0 & 3.5 & 3.2 & 6.5 & 6.0 & 7.5 & 15.0 & \multirow[t]{3}{*}{$1.300^{5}$} \\
\hline & \multirow[t]{2}{*}{5876} & \multirow[t]{2}{*}{ AT } & Dis.\% & 7.7 & 7.1 & 5.1 & 3.7 & 3.5 & 3.0 & 7.0 & 6.5 & 8.0 & \multirow[t]{2}{*}{16.0} & \\
\hline & & & Nul.\% & 7.0 & 7.0 & 4.9 & 3.9 & 3.6 & 3.1 & 6.9 & 6.6 & 7.7 & & \\
\hline \multirow[t]{2}{*}{22} & 6209 & BT & Dis. \% & 7.0 & 6.9 & 5.5 & 4.5 & 3.8 & 3.2 & 6.8 & 6.0 & 7.9 & 15.8 & \multirow[t]{2}{*}{$1.234^{\mathrm{s}}$} \\
\hline & 5891 & AT & Nul.\% & 6.9 & 6.0 & 4.0 & 3.8 & 2.9 & 3.0 & 6.4 & 5.7 & 7.4 & 14.2 & \\
\hline \multirow[t]{4}{*}{23} & \multirow[t]{2}{*}{5901} & \multirow[t]{2}{*}{ BT } & Dis.\% & 4.5 & 4.3 & 3.2 & 3.0 & 1.9 & 2.0 & 4.0 & 3.7 & 5.1 & \multirow[t]{2}{*}{10.2} & \multirow[t]{4}{*}{$1.786^{\mathrm{s}}$} \\
\hline & & & Nul.\% & 4.6 & 4.4 & 3.0 & 2.8 & 1.7 & 1.8 & 3.9 & 3.5 & 5.4 & & \\
\hline & \multirow[t]{2}{*}{5980} & \multirow[t]{2}{*}{ AT } & Dis.\% & 3.9 & 3.5 & 2.8 & 2.4 & 2.0 & 1.9 & 3.5 & 3.0 & 4.5 & \multirow[t]{2}{*}{9.0} & \\
\hline & & & Nul.\% & 3.7 & 3.7 & 2.9 & 2.7 & 1.9 & 2.2 & 3.6 & 3.4 & 4.7 & & \\
\hline
\end{tabular}

Abbreviations: AT, after therapy; BT, before therapy; FISH, fluorescent in situ hybridisation; OAT, oligoasthenoteratospermia.

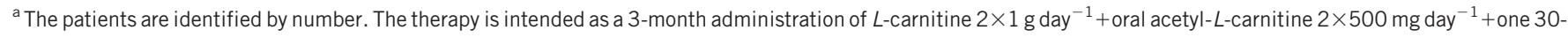
mg Cinnoxicam tablet every 4 days. The percentages of disomic (Dis.\%) and nullisomic sperm (Nul.\%) in each individual patient for chromosomes X, Y, 13, 15, 16, 17, 18, 21 and 22 are listed. The percentage of sperm aneuploidy was presented and calculated by doubling the incidence of disomy (see the 'Materials and methods' section). $* P<0.05, * * P<0.01,{ }^{\S} P>0.05$, total percentage of aneuploid sperm for BT vs. AT, using $\chi^{2}$ test.

of SISMER strongly discourage patients from participating in a study in which approximately half of them would be administered a placebo. To overcome this problem, we used two strategies. First, we compared the patients that exhibited reductions in their sperm aneuploidy levels (group 1) and the patients in whom there was no reduction (group 2). It was possible to plan this kind of comparison a priori, because idiopathic OAT has multiple aetiologies, ${ }^{13}$ and carnitines improve semen parameters only in the presence of the normal activity of mitochondrial phospholipid hydroperoxide glutathione peroxidase. ${ }^{24}$ Second, we evaluated the intra-individual variability of the FISH test results in 15 cases, and there were no significant differences. Tempest et al. ${ }^{25}$ analysed the intra-individual aneuploidy levels in 10 normospermic patients and found sporadic significant variation; similar results were reported by Rubes et al. ${ }^{26}$ in 15 normospermic smoker sperm donors. These results regarding intra-individual variability might seem to contradict ours. However, it could be hypothesized that these differences are due to the different populations studied. Our research considered non-smokers with severe idiopathic OAT, and the literature agrees that in oligoasthenoteratospermic patients, the intra-individual variability is not significant. ${ }^{27,28}$

Italian law limits the efficiency of assisted reproduction treatment in couples with a severe male factor. ${ }^{29}$ Therefore, approximately one-half of couples needing assisted reproduction travel abroad for fertility treatments. ${ }^{30}$ This made the recruitment of couples for the present paper particularly difficult. Although sperm morphology is an independent characteristic with respect to concentration and motility, which, by contrast, are directly linked to each other, ${ }^{13}$ we were compelled to recruit couples arbitrarily only on the basis of sperm concentration to avoid an excessively long study period.

We analysed the incidence of sperm aneuploidies in severe idiopathic OAT patients, irrespective of whether they had a significant increase in anomalies with respect to the control population. It is likely that the DNA damage assessed in the present paper with respect to chromosomes X, Y, 13, 15, 16, 17, 18, 21 and 22 using FISH represents only a portion of the DNA damage that could be identified by testing all 23 chromosomes. We thus postulated that treating only those severe idiopathic OAT patients in whom the frequency of sperm aneuploidies for the chromosomes studied was higher than the control population might deprive some severe idiopathic OAT patients of the potential benefits of the therapy.

The molecular causes of germ cell meiotic defects are not well known. Alterations of folate, zinc and antioxidant intake $e^{7,31}$ may be responsible for increased levels of sperm aneuploidy in infertile men. We administered antioxidant compounds; thus, the hypothesis that reactive oxygen species might affect sperm aneuploid levels is possible. In fact, three patients (see Table 2, patients 1, 2 and 10) who had successfully fathered children and reduced their sperm aneuploidy frequencies after the first course of therapy requested a second ICSI. They underwent FISH tests at 24, 32 and 36 months after the first ICSI cycle, and the percentages of aneuploid sperm were $21.1 \%, 15.9 \%$ and $14.7 \%$, respectively; these percentages are similar to the first FISH test carried out $(22.0 \%, 17.2 \%$ and $14.9 \%$, respectively). These patients underwent a second therapeutic cycle, and all of them exhibited significantly reduced sperm aneuploid frequencies $(4.7 \%, 5.1 \%$ and

Table 3 Data for the semen parameters of patients who exhibited significant reductions in their sperm aneuploidy levels and those for whom no reduction was observed before and after the therapy (administration of Cinnoxicam $+L$-carnitine/acetyl- $L$-carnitine). The sperm count is the median value of two rounds of counting (see the 'Materials and methods' section)

\begin{tabular}{|c|c|c|c|c|}
\hline \multirow[t]{2}{*}{ Variables assessed, median (range) } & \multicolumn{2}{|c|}{ Group $1(\mathrm{n}=22)$} & \multicolumn{2}{|c|}{ Group $2(\mathrm{n}=11)$} \\
\hline & Before therapy & After therapy & Before therapy & After therapy \\
\hline Sperm concentration $\left(\times 10^{6} \mathrm{ml}^{-1}\right)$ & $0.9(0.1-1.9)$ & $1.0(0.2-1.9)$ & $1.4(0.6-1.9)$ & $1.5(0.7-1.8)$ \\
\hline Percentage of WHO class a motile sperm & $1.9(0-4.1)$ & $2(0-4.0)$ & $1(0-3)$ & $1(0 .-3)$ \\
\hline Percentage of typical forms (strict criteria) & $3(0-12)$ & $7.5(4-11)$ & $4(0-10)$ & $4(1-9) *$ \\
\hline Percentage of aneuploid spermatozoa & $15(9-19)$ & $2.0(0.08-5.0)$ & $17(10-20)$ & $16(8.0-18)^{*}$ \\
\hline
\end{tabular}

$* P<0.01$, compared with group 1 after therapy. 
Table 4 The ICSI variables of the partners of patients who exhibited significantly reduced sperm aneuploidy levels (group 1) and those in whom there was no reduction (group 2) after the therapy (administration of Cinnoxicam $+L$-carnitine/acetyl- $L$-carnitine). The percentages of biochemical pregnancies, clinical pregnancies, miscarriages and live births were calculated using the number of ICSI cycles as denominator

\begin{tabular}{lcc}
\hline Variables assessed & Group $1(\mathrm{n}=22)$ & Group 2 $(\mathrm{n}=11)$ \\
\hline Oocytes collected, $n$ & 174 & 65 \\
Number of oocytes injected, $n(\%)$ & $76(43.7 \%)$ & $33(50.8 \%)$ \\
Oocytes fertilized, $n(\%)$ & $56(73.7 \%)$ & $29(87.9 \%)$ \\
Embryos transferred, $n(\%)$ & $41(73.2 \%)$ & $23(79.3 \%)$ \\
Biochemical pregnancies, $n(\%)$ & $12(54.4 \%)$ & $1(9.1 \%)$ \\
Clinical pregnancies, $n(\%)$ & $11(50.0 \%)$ & $1(9.1 \%) *$ \\
Miscarriages, $n(\%)$ & $1(4.5 \%)$ & $0(0 \%)$ \\
Live births, $n(\%)$ & $10(45.4 \%)$ & $1(9.1 \%)^{*}$ \\
ICSI cycles performed, $n$ & 25 & 11 \\
\hline
\end{tabular}

$* P<0.01$, compared with group 1 after therapy.

$3.2 \%$, respectively); two of them successfully fathered children again. However, the absence of a control group does not permit eliminating a possible placebo effect and/or an activity of the vehicles used in drug production. However, our data agree with previous studies indicating that the reversal of DNA damage (assessed with DNA fragmentation tests) achieved with antioxidant drugs has a beneficial effect on ICSI outcomes. ${ }^{32-34}$ The possibility of the drug-induced degeneration of sperm cells with abnormal chromosome content may constitute an additional hypothesis that could explain our results.

The influence of lifestyle and environmental factors on sperm aneuploidy levels might be regarded as negligible in the present study; tobacco and alcohol users were excluded. In addition, the patients were instructed not to change their diet, and all patients confirmed that no diet changes occurred. Reproductive safety, exposure to pesticides, heat, magnetic fields, ultrasound and any other potential reproductive hazards in the work place are strictly regulated by Italian law (http://www.bio.unipd.it/safety/man/norme.html), which is considered to be the strictest in Europe. Italian law requires that work places maintain levels of these hazards below thresholds regarded as not dangerous to human reproductive health.

Our data demonstrate that the patients in group 1 (responders) had higher rates of biochemical/clinical pregnancies and live births, but not fertilisation events and embryo transfers compared with group 2 (non-responders) after drug administration. An increased level of DNA damage during in vitro fertilisation correlated with abnormal embryo morphology, decreased pregnancy rates, increased spontaneous abortions and failure to progress to the blastocyst stage in culture, whereas fertilisation and the early stages of development did not seem to be affected by DNA sperm quality. ${ }^{3}$ Interestingly, in an unused embryo derived from semen samples exhibiting high DNA fragmentation, mitosis was stopped at the six-to-eight-cell stage, which coincides with the full activation of the embryonic genome. ${ }^{35}$ Fertilisation and two-to-four-cell-stage embryogenesis might be able tolerate some amount of DNA damage in the fertilizing sperm due to the upregulation of the DNA repair mechanism and cell cycle delay. ${ }^{36}$ The sperm and egg genomes are transcriptionally inactive during the period that encompasses fertilisation. Mammalian embryos use maternal compounds, protein and transcripts inherited from the oocyte to initiate development. The embryonic genome begins to be transcribed at the two-cell stage in the mouse and at the four-to-eight-cell stage in humans. After this transition, maternal transcripts are steadily degraded. ${ }^{37}$
Our team has previously shown that Cinnoxicam suppositories and $L$-carnitine/acetyl- $L$-carnitine treatment significantly improve sperm concentration, motility and morphology in idiopathic OAT patients, ${ }^{10}$ and an increase in of the percentage of normal sperm was observed in this study, where Cinnoxicam tablets were used. Suppositories were no longer marketed after 2004; therefore, we were compelled to use tablets. Additionally, in the previous study, we treated patients with a sperm concentration $>5 \times 10^{6} \mathrm{ml}^{-1}$, whereas in this study, we evaluated a different population (i.e., idiopathic OAT with sperm concentration $<2 \times 10^{6} \mathrm{ml}^{-1}$ ). The different populations studied and the different means of Cinnoxicam administration ${ }^{10}$ might explain the different results in terms of sperm concentration, motility and morphology. One previously published study reported improved semen parameters and reduced sperm aneuploidy levels ${ }^{7}$ at the same time, whereas two others only reported reduced sperm aneuploidy levels. Tempest et al. ${ }^{8}$ used traditional Chinese medicine, and Piomboni et al. ${ }^{9}$ used human recombinant FSH therapy. These differences may be explained by differences in the populations studied and the therapeutic regimens.

In conclusion, our data indicate that the investigation of therapies capable of improving sperm DNA arrangements may become a critical field of interest for improving the likelihood of OAT patients fathering children through ICSI.

\section{AUTHOR CONTRIBUTIONS}

GC wrote the paper and examined the male patients. MCM and AC reviewed the paper and performed the sperm analysis, FISH analyses and ICSI procedures. APF and LG examined the female patients and performed the ICSI procedures.

\section{COMPETING FINANCIAL INTERESTS}

The authors declare no financial interest.

1 Carrel DT. The clinical implementation of sperm chromosome aneuploidy testing: pitfalls and promises. J Androl 2008; 9: 124-33.

2 Nicollopoulos J, Gilling-Smith C, Alameida PA, Homa S, Nice L et al. The role of sperm aneuploidy as a predictor of the success of intracytoplasmic sperm injection. Hum Reprod 2008; 23: 240-5

3 Emery BR, Carrel DT. The effect of epigenetic sperm abnormalities on early embryogenesis. Asian J Androl 2006; 8: 131-42.

4 Burrello N, Vicari E, Shin P, Agarwal A, de Palma A et al. Lower sperm aneuploidy frequency is associated with high pregnancy rates in ICSI programmes. Hum Reprod 2003; 18: 1371-6.

5 Bonduelle M, Liebaers I, Deketelaere V, Derde VM, Camus M et al. Neonatal data on a cohort of 2889 infants born after ICSI (1991-1999) and of 2995 infants born after IVF (1983-1999). Hum Reprod 2002; 17: 671-94.

6 Hindryckx A, Peeraer K, Debrock S, Legius E, de Zegher F et al. Has the prevalence of congenital abnormalities after intracytoplasmic sperm injection increased? The Leuven data 1994-2000 and a review of the literature. Gynecol Obstet Invest 2010; 29: 11-22.

7 Baccetti BM, Bruni E, Capitani S, Collodel G, Mancini S et al. Studies on varicocele III: ultrastructural sperm evaluation and 18, X, and Y aneuploidies. J Androl 2006; 27: 94-101.

8 Tempest HG, Homa ST, Zhai XP, Griffin DK. Significant reduction of sperm disomy in six men: effect of traditional Chinese medicine? Asian J Androl 2005; 7: 419-25

9 Piomboni P, Serafini F, Gambera L, Musacchio C, Collodel G et al. Sperm aneuploidies after human recombinant follicle stimulating hormone therapy in infertile males. Reprod Biomed Online 2009; 18: 622-9.

10 Cavallini G, Ferraretti AP, Gianaroli L, Biagiotti G, Vitali G. Cinnoxicam and Lcarnitine/acetyl- $L$-carnitine treatment for idiopathic and varicocele associated oligoasthenoteratospermia. J Androl 2004; 25: 761-70.

11 World Health Organization. WHO laboratory manual for the examination of human semen and semen-cervical mucus interaction. 4th ed. Cambridge: Cambridge University Press; 1999.

12 Casper RF, Mitwally MFM. Aromatase inhibitors for ovulation induction. J Clin Endocrinol Metab 2006; 91: 760-71. 
Reduction in sperm aneuploidies

G Cavallini et al

598

13 Cavallini G, Cripps A, Magli MC, Cavallini N, Ferraretti AP et al. A study to sustain the hypothesis of the multiple genesis of oligoasthenoteratospermia in idiopathic infertile males. Biol Reprod 2008; 79: 667-73.

14 Van der Merwe FH, Kruger TF, Oehninger SC, Lombard CJ. The use of semen parameters to identify the subfertile male in the general population. Gynecol Obstet Invest 2005; 59: 86-91.

15 Gianaroli L, Magi MC, Cavallini G, Crippa A, Nadalini M et al. Frequency of aneuploidy in sperm from patients with extremely severe male factor infertility. Hum Reprod 2005; 20: 2140-52.

16 Armitage P. Statistical Methods in Medical Research. Oxford: Blackwell Scientific Publishers; 1971.

17 Ferraretti AP, Magli MC, Kopcow L, Gianaroli L. Prognostic role of preimplantation genetic diagnosis for aneuploidy in assisted reproduction technology outcome. Hum Reprod 2004; 13: 694-9.

18 Goodman SN. Stopping at nothing? Some dilemmas of data monitoring in clinical trails. Ann Intern Med 2007; 146: 882-7.

19 Vendrell JM, Arán B, Vega A, Garcia F, Coroleu B et al. Spermatogenic patterns and early embryo development after intracytoplasmic sperm injection in severe oligoasthenozoospermia. J Assist Reprod Genet 2003; 20: 106-12.

20 Chou XP, Bu XL, Zhu YM, Qu F, Sun SJ et al. Comparison of semen quality and outcome of assisted reproductive techniques in Chinese men with and without hepatitis $B$. Asian J Androl2011; 13: 465-9

21 Clark YS, Lee SH, Song SJ, Jun JH, Mong MK et al. Influence of motility on the outcome of in vito fertilization/intracytoplasmic sperm injection with fresh vs. frozen testicular sperm from men with obstructive azoospermia. Fertil Steril 2003; 80: 526-30.

22 Templado C, Vidal F, Estop A. Aneuploidy in human spermatozoa. Cytogenet Genome Res 332011; 91-9.

23 Strassburger D, Reichart M, Kaufman S, Kasterstein E, Komarovsky D et al. Morphology assessment and fluorescence in situ hibridation of the same spermatozoon using a computerized cell-scanning system. Hum Reprod 2007; 22: 201-9.

24 Garolla A, Maiorino M, Roverato A, Roveri A, Ursini F et al. Oral carnitine supplementation increases sperm motility in asthenozoospermic men with normal sperm phoshpholipid hydroperoxide glutathione peroxidase levels. Fertil Steril 2005; 83: 355-61.
25 Tempest HG, Ko E, Rademaker A, Chan P, Robaire B et al. Intra-individual and interindividual variations in sperm aneuploidy frequencies in normal men. Fertil Steril 2009; 91: 185-92

26 Rubes J, Vozdova M, Robbins WA, Rezacova O, Perrault SD et al. Stable variants of sperm aneuploidy among healthy men show associations between germinal and somatic aneuploidy. Am J Hum Genet 2002; 70: 1507-19.

27 Ushijima C, Kumasako Y, Kihaile PE, Hirotsuru K, Utsunomiya T. Analysis of chromosomal abnormalities in human spermatozoa using multicolour fluorescence in-situ hybridization. Hum Reprod 2000; 15: 1107-11.

28 Kia Y, Chen S, Ban Q, Xu L, Collins MD et al. Genotoxic effects on spermatozoa of carbaryl-exposed workers. Toxicol Sci 2005; 85: 615-23.

29 La Sal GB, Nicoli A, Capodanno F, Rondini I, Villani MT et al. The effect of the 2004 Italian law on outcomes of assisted reproduction technology in severe male factor infertility. Reprod Boomed Online 02010; 2-10.

30 Zanini G. Abandoned by the State, betrayed by the Church: Italian experiences of cross-border reproductive care. Reprod Boomed Online 2011; 23: 565-72.

31 Young SS, Eskenazi B, Marchetti FM, Block G, Wyrobek AJ. The association of folate, zinc and antioxidant intake with sperm aneuploidy in health non smoking men. Hum Reprod 2008; 23: 1014-22.

32 Greco E, Romano S, lacobelli M, Ferrero S, Baroni E et al. ICSI in cases of sperm DNA damage: beneficial effect of oral antioxidant treatment. Hum Reprod 2005; 20: 2590-4.

33 Tremellen K, Mari G, Froiland D, Thompson J. A randomized controller trial examining the effect of an antioxidant (Menevit) on pregnancy outcome during IVF-ICSI treatment. Aust NZ J Obstet Gynaecol 2007; 47: 216-21.

34 Lombardo F, Gandini L, Lenzi A. Treatment of idiopathic oligoasthenoteratospermia. In:Cavallini G, editor. An Updating for Andrology. Kerala (India): Transworld Reasearch Network; 2008. pp114-24.

35 Virant Klan I, Tomazevic T, Meden Vrotek H. Sperm single stranded DNA, detected by acridine orange staining reduces fertilization and quality of ICSI derived embryos. $J$ Ass Reprod Gen 2002; 19: 319-28.

36 Shimura T, Inohue M, Toga M, Shiraishi K, Uematsu M et al. p53 dependent s-phase chepoint and pronuclear cross-talk in mouse zygotes with X irradiated sperm. Mol Cell Biol 2002; 22: 2220-8.

37 Hardy K, Spans S. Growth factor expression and function in the human and mouse preimplantation embryo. J Endocrinol 2002; 172: 221-36.

Asian Journal of Andrology 